\title{
Neonatal Respiratory System Disorder
}

National Cancer Institute

\section{Source}

National Cancer Institute. Neonatal Respiratory System Disorder. NCI Thesaurus. Code C99232.

A respiratory system disorder that occurs during the neonatal period. A representative example is the respiratory distress syndrome. 